Chapman University

Chapman University Digital Commons

Psychology Faculty Articles and Research

Psychology

2011

\title{
A Prospective Study of Positive Psychological Well- Being and Coronary Heart Disease
}

Julia K. Boehm

Chapman University, jboehm@chapman.edu

Christopher Peterson

University of Michigan

Mika Kivimaki

University College London

Laura D. Kubzansky

Harvard School of Public Health

Follow this and additional works at: http://digitalcommons.chapman.edu/psychology_articles

Part of the Cardiovascular Diseases Commons, Health Psychology Commons, Other Psychiatry and Psychology Commons, and the Psychological Phenomena and Processes Commons

\section{Recommended Citation}

Boehm, Julia K., et al. (2011). "A prospective study of positive psychological well-being and coronary heart disease." Health Psychology 30(3), 259. doi:10.1037/a0023124

This Article is brought to you for free and open access by the Psychology at Chapman University Digital Commons. It has been accepted for inclusion in Psychology Faculty Articles and Research by an authorized administrator of Chapman University Digital Commons. For more information, please contactlaughtin@chapman.edu. 


\section{A Prospective Study of Positive Psychological Well-Being and Coronary Heart Disease}

\section{Comments}

This is a pre-copy-editing, author-produced PDF of an article accepted for publication in Health Psychology, volume 30, issue 3, 2011 following peer review. The definitive publisher-authenticated version is available online at DOI: $10.1037 / \mathrm{a} 0023124$.

This article may not exactly replicate the final version published in the APA journal. It is not the copy of record.

\section{Copyright}

American Psychological Association 


\title{
A Prospective Study of Positive Psychological Well-Being and Coronary Heart Disease
}

\author{
Julia K. Boehm, Ph.D., Christopher Peterson, Ph.D., Mika Kivimaki, Ph.D., and Laura \\ Kubzansky, Ph.D. \\ Department of Society, Human Development, and Health, Harvard School of Public Health (J.B., \\ L.K.), Boston; Department of Psychology, University of Michigan (C.P.), Ann Arbor; Department \\ of Epidemiology and Public Health, University College London (M.K.), London
}

\begin{abstract}
Objective-Research suggests that positive psychological well-being is associated with cardiovascular health. However, much of this research uses elderly samples and has not determined the pathways by which psychological well-being influences cardiovascular disease or whether effects are similar for men and women. This study investigates the association between two aspects of well-being (emotional vitality and optimism) and coronary heart disease (CHD) in a sample of middle age men and women, and considers potential mediating factors.
\end{abstract}

Methods-Between 1991 and 1994, well-being and coronary risk factors were assessed among 7,942 individuals without a prior cardiovascular event from the Whitehall II cohort. Incident CHD (fatal CHD, first nonfatal myocardial infarction, or first definite angina) was tracked during 5 person-years of follow-up.

Results-Positive psychological well-being was associated with reduced risk of CHD with an apparent threshold effect. Relative to people with the lowest levels of well-being, those with the highest levels had minimally-adjusted hazard ratios of 0.74 (95\% confidence interval: $0.55-0.98$ ) for emotional vitality and 0.73 (95\% confidence interval: $0.54-0.99$ ) for optimism. Moreover, the association was strong for both genders and was only weakly attenuated when accounting for illbeing. Neither health-related behaviors nor biological factors explained these associations.

Conclusions-Positive psychological well-being was associated with a modest but consistent reduced risk of incident CHD. The relationship was comparable for men and women, and was maintained after controlling for cardiovascular risk factors and ill-being. Additional research is needed to identify underlying mechanisms and investigate whether interventions to increase wellbeing may enhance cardiovascular health.

\section{Keywords}

cardiovascular disease; coronary heart disease; well-being; vitality; optimism

A growing body of evidence suggests that psychological health may influence physical health. Most of the research to date has focused on psychological ill-being, with less

Correspondence and reprint requests to: Dr. J. Boehm, Department of Society, Human Development, and Health, Harvard School of Public Health, 401 Park Drive, Boston, MA 02215; Phone: 617-384-8777; Fax: 617-432-3123; jboehm@ @sph.harvard.edu.

Publisher's Disclaimer: The following manuscript is the final accepted manuscript. It has not been subjected to the final copyediting, fact-checking, and proofreading required for formal publication. It is not the definitive, publisher-authenticated version. The American Psychological Association and its Council of Editors disclaim any responsibility or liabilities for errors or omissions of this manuscript version, any version derived from this manuscript by NIH, or other third parties. The published version is available at www.apa.org/pubs/journals/hea 
research examining whether and how positive psychological well-being influences physical health outcomes. Because psychological ill-being and well-being are not direct opposites of one another, the absence of negative functioning need not imply the presence of positive functioning (Ryff \& Singer, 1998). Thus, evidence for associations between psychological ill-being and physical health do not indicate whether positive psychological well-being is associated with physical health, or if such associations are independent of psychological illbeing. The present research focuses on positive psychological well-being and its association with coronary heart disease (CHD), one of the leading causes of death in the U.S. and worldwide (Mathers \& Loncar, 2006; Xu, Kochanek, Murphy, \& Tejada-Vera, 2010).

\section{Positive Psychological Well-Being}

In contrast to psychological ill-being (i.e., pervasive negative feelings and poor functioning in life), positive psychological well-being (or "well-being") reflects the positive components of psychological health that characterize individuals who feel good about life and function well (Keyes \& Annas, 2009). Well-being is a broad construct that encompasses a variety of theoretical approaches including eudaimonic well-being, hedonic well-being, and social well-being (Gallagher, Lopez, \& Preacher, 2009). Each approach emphasizes different facets of well-being and is characterized by different constructs. Eudaimonic well-being emphasizes functioning in life and assesses constructs like purpose in life and optimism. Hedonic well-being emphasizes cognitive and affective evaluations of life and assesses constructs like life satisfaction and positive feelings. Social well-being emphasizes functioning in the social realm and assesses constructs like social integration and social contribution. Although some skepticism exists regarding the extent to which the different approaches to positive psychological well-being can be separated (Kashdan, Biswas-Diener, \& King, 2008), most researchers consider them to be related but distinct (Gallagher et al., 2009; Keyes \& Annas, 2009). Thus, multiple constructs are included under the broad category of positive psychological well-being and then further described according to more specific approaches to well-being.

\section{Positive Psychological Well-Being and Coronary Heart Disease}

Researchers posit that positive psychological well-being may influence health by buffering against the effects of stress (Rozanski \& Kubzansky, 2005) and regulating behavior through processes of engagement and disengagement (Scheier \& Carver, 1985). Indeed, evidence suggests that positive psychological well-being is associated with cardiovascular health. For example, optimism is associated with reduced risk of incident CHD and reduced cardiovascular mortality (Giltay, Kamphuis, Kalmijn, Zitman, \& Kromhout, 2006; Kubzansky, Sparrow, Vokonas, \& Kawachi, 2001; Tindle et al., 2009). Reports of emotional vitality (Kubzansky \& Thurston, 2007) and displays of positive affect (Davidson, Mostofsky, \& Whang, 2010) are also associated with reduced risk of CHD, although some null findings have been reported as well (Nabi, Kivimaki, De Vogli, Marmot, \& SinghManoux, 2008). Moreover, studies from Japan have demonstrated that ikigai - defined as having a life worth living - is associated with reduced cardiovascular mortality (Koizumi, Ito, Kaneko, \& Motohashi, 2008; Tanno et al., 2009).

Previous studies have not sufficiently addressed key issues relevant to the association between positive psychological well-being and CHD. One issue concerns the specific mechanisms by which well-being is involved in the etiology of CHD. Well-being may indirectly affect CHD through health behaviors such as improved diet and increased physical activity (Giltay, Geleijnse, Zitman, Buijsse, \& Kromhout, 2007; Steptoe, Wright, Kunz-Ebrecht, \& Iliffe, 2006) or well-being may directly affect CHD through alterations in the neuroendocrine, cardiovascular, and inflammatory systems (Steptoe, Dockray, \& 
Wardle, 2009). Another issue concerns whether well-being's protective effect is the same for men and women. Some studies have considered the association between well-being and CHD in samples composed exclusively of one gender or the other (Kubzansky et al., 2001; Tindle et al., 2009). Other studies have found effects for men only (Koizumi et al., 2008; Tanno et al., 2009), although this could be due to limited case counts among women. Finally, past research has usually investigated the relationship between well-being and cardiovascular health in older adults (Giltay et al., 2006). However, predictive relationships with CHD tend to weaken at older ages (Yusuf et al., 2004) and well-being may affect CHD in unique ways at different life stages. It is therefore important to establish that well-being in relatively younger adults is also associated with incident CHD.

The present research sought to investigate the association between well-being and incident CHD in a prospective cohort of predominantly middle-age men and women from the Whitehall II study. Two indicators of well-being previously linked with CHD were considered - namely, emotional vitality and optimism. These constructs may be potentially important for cardiovascular health because they emphasize positive functioning (i.e., eudaimonic well-being). The current investigation specifically examined: 1) possible pathways underlying the association between well-being and CHD, 2) whether effects of well-being were independent of ill-being, 3) whether the association between well-being and CHD was characterized by threshold effects, 4) whether the association between well-being and CHD is similar for men and women, and 5) whether the association between well-being and CHD is similar for older versus younger individuals.

\section{Methods}

\section{Participants}

Participants in the Whitehall II study included an initial cohort of 10,308 British civil servants followed since 1985-1988 (Phase 1) (Marmot et al., 1991). For the present investigation, Phase 3 (1991-1994) was considered the baseline because emotional vitality and optimism were measured then. Two hundred eighty participants who experienced a cardiovascular-related event between Phases 1 and 3 were excluded. Of those remaining 10,028 participants, 103 died before participation at Phase 3 and 1,349 were withdrawn for non-response, leaving 8,576. Six hundred thirty four people were also excluded due to missing values of emotional vitality, optimism, or the outcomes, yielding an analytic sample of 7,942 .

The Whitehall II study was approved by the joint Human Research Ethics Committees at the University College London and the University College London Hospital. The current investigation was approved for exemption by the Harvard School of Public Health Institutional Review Board. All participants provided written informed consent.

\section{Measures of Positive Psychological Well-Being}

The Whitehall II study was established to understand the relationship between socioeconomic status and health. Because well-being was not a primary focus of the research initially, well-developed measures were not included and available measures are limited. To address these limitations and increase confidence in the robustness of the findings, two indicators of well-being - emotional vitality and optimism - were used. These indicators were developed by considering all relevant items from Phase 3 and then deriving measures (blind to the outcome) from theory and empirical research.

Emotional vitality - defined as active engagement with the world, effective emotional regulation, and an overall sense of well-being - was measured with five items highly similar to those used in previous studies. Items included "I have a sense of direction and purpose in 
my life," "How often do you feel emotionally or mentally exhausted at the end of the day (reverse scored)," and three items from the Short Form-36 (Ware \& Sherbourne, 1992): "How much of the time during the past 4 weeks did you feel full of life," "... have a lot of energy," "...have you been a happy person." Because of different response scales, items were standardized $(M=0, S D=1)$ and then averaged to form a composite with good internal consistency reliability $(\alpha=.79)$ and strong face validity. Higher scores indicate greater emotional vitality.

Optimism was assessed with the single item "Over the next 5-10 years, I expect to have many more positive than negative experiences," which participants rated on a 6-point Likerttype scale $(1=$ strongly disagree, $2=$ moderately disagree, $3=$ slightly disagree, $4=$ slightly agree, $5=$ moderately agree, $6=$ strongly agree $)$. Because optimism is defined as the expectation that more good than bad things will happen in life (Scheier \& Carver, 1985), this single item was deemed to be face valid and adequate for subsequent analyses.

Emotional vitality and optimism were moderately correlated $(r=.51)$. In addition, the two measures of well-being correlated with other psychosocial variables as expected. Emotional vitality and optimism were negatively correlated with ill-being (discussed in more detail below; $r=-.45$ and -.22 , respectively) and having less meaning in life $(r=-.46$ and -.39 , respectively). Moreover, emotional vitality and optimism were positively correlated with satisfaction across life domains ( $r=.58$ and .39 , respectively) and having people to count on $(r=.33$ and .35 , respectively). Given these patterns of correlations, emotional vitality and optimism were considered to have construct validity. Overall, considering assessment of both reliability and validity, these indicators of well-being appeared to provide reasonable measures of the intended constructs.

Natural or clinically-based thresholds have not been defined for these measures of wellbeing. Thus, tertiles were created based on the distribution of scores to assess threshold effects, which determine whether the association between each measure of positive psychological well-being and CHD was evident at all levels of exposure. For emotional vitality, standardized scores $\leq-0.38$ were low $(33.2 \%)$, scores from -0.38 to 0.54 were moderate $(33.8 \%)$, and scores $\geq 0.54$ were high $(33 \%)$. For optimism, standardized scores from -3.14 to -0.54 were low (37\%), scores of 0.31 were moderate $(39.5 \%)$, and scores of 1.18 were high $(23.5 \%)$. Tertiles were selected rather than quartiles or quintiles because tertiles yielded the most even distribution of participants across groups.

\section{Measures of Morbidity and Mortality}

Incident CHD was assessed from Phase 3 to Phase 5 (1997-1999), a mean follow-up of 5.43 person-years $(S D=1.23)$. Incident $C H D$ included fatal CHD, first nonfatal myocardial infarction (MI), or first definite angina. The British National Health Service Central Registry provided the date and cause of all participant deaths. Coronary-related deaths were classified according to codes $410-414$ from the $9^{\text {th }}$ revision of the International Classification of Diseases and codes I20-I25 from the $10^{\text {th }}$ revision. Criteria from the World Health Organization's Monitoring Trends and Determinants of Cardiovascular Disease Project was used to confirm nonfatal MI (Tunstall-Pedoe et al., 1994). These included study electrocardiograms, hospital acute electrocardiograms, and cardiac enzymes. Definite angina was established by clinical records and nitrate medication use, and excluded self-report that was not clinically verified (Rose, Blackburn, Gillum, \& Prineas, 1982). Two trained coders classified cardiac events and reached agreement on discrepancies. 


\section{Measures of Cardiovascular Risk Factors}

Demographic covariates included age (years), gender (male, female), ethnicity (white, nonwhite), marital status (married/cohabitating, other), and grade of employment (administrative, professional, clerical). Within the U.K. civil service classification, administrative levels are the highest employment grade. Covariates related to health behaviors included smoking status (current, former, never), alcohol consumption (units of alcohol in the past week), hours exercised (combined hours per week of mild, moderate, and vigorous exercise), and daily fruit and vegetable consumption (yes, no). Covariates related to blood pressure and metabolic functioning included systolic blood pressure (SBP; mm $\mathrm{Hg}$ ), diastolic blood pressure (DBP; mm Hg), high-density lipoprotein cholesterol (HDL-C; $\mathrm{mmol} / \mathrm{L}$ ), low-density lipoprotein cholesterol (LDL-C; $\mathrm{mmol} / \mathrm{L}$ ), triglycerides $(\mathrm{mmol} / \mathrm{L}$ ), body mass index (BMI; $\mathrm{kg} / \mathrm{m}^{2}$ ), and known diabetes (yes, no). Psychological ill-being was indexed by Short Form-36 items that asked whether emotional problems like depression or anxiety caused individuals to 1) "Cut down the amount of time you spent on work or other activities," 2) "Accomplished less than you would like," and 3) "Didn't do work or other activities as carefully as usual" (Ware \& Sherbourne, 1992). Participants responded to these items with "yes" (coded 1) or "no" (coded 0 ) and then received a score based on the sum of their "yes" responses, such that high scores indicated greater ill-being $(\alpha=.78)$. Although the effects of two other ill-being measures were examined - a 2-item stress composite $(\alpha=$. 77) and a 5-item depression composite $(\alpha=.80)$ - only findings for the first ill-being measure are presented as this was the least highly collinear with well-being. However, the ill-being findings reported were very similar regardless of which ill-being measure was used. All covariates and ill-being were measured at the Phase 3 baseline with the exception of gender and ethnicity, which were measured at Phase 1. Blood pressure, lipids, and BMI were assessed in medical examinations whereas the remaining covariates were assessed by self-report.

\section{Statistical Analyses}

Consistent with Graham (2009), multiple imputation procedures (PROC MI and MIANALYZE; SAS Institute Inc) were used to impute missing values on covariates and pool estimates from five imputed datasets. Cox proportional hazards regression models (PROC PHREG; SAS Institute Inc) were used to estimate hazard ratios (HR) of incident CHD and $95 \%$ confidence intervals (CI). Research on other potential protective factors for incident CHD have identified reductions in relative risk ranging from $8 \%$ (regular alcohol consumption) to $14 \%$ (regular physical activity) to $30 \%$ (daily consumption of fruits and vegetables) (Yusuf et al., 2004). Other work has found reductions in risk ranging from $25 \%$ per standard deviation change in optimism to $2 \%$ per unit change in emotional vitality (Kubzansky et al., 2001; Kubzansky \& Thurston, 2007). The time-dependent interaction terms between each well-being indicator and logarithm of follow-up period were all nonsignificant $(p>0.50)$, confirming that the proportional hazards assumption was justified.

Using a continuous measure of well-being, regression analyses started with age-adjusted models (Model 1), followed by minimally-adjusted models controlling for demographics (Model 2; age, gender, ethnicity, marital status, employment grade). To examine underlying pathways between well-being and CHD, models that adjusted for health behaviors (Model 3; smoking status, alcohol consumption, exercise, fruit and vegetable consumption) and blood pressure/metabolic factors (Model 4; SBP, DBP, HDL-C, LDL-C, triglycerides, BMI, diabetes)were considered next. The final model included all covariates and also accounted for ill-being (Model 5). In addition, the independent effect of ill-being in the full multivariate model was examined. To investigate whether threshold effects were present, well-being tertiles were included in minimally-adjusted and multivariate-adjusted models. Models were stratified by gender to evaluate differences between men and women, and by 
age to evaluate differences between individuals who were $\leq 54$ years versus 55 years and older.

Additional secondary analyses used different CHD definitions (i.e., including and excluding definite angina) and excluded individuals who experienced a cardiovascular event within the first person-year of baseline or who had diabetes. To ensure that people with treated hypertension were not unduly influential, individuals who had been told by a physician that they had high blood pressure at Phase 1 and, second, those who had been told at Phases 1, 4, or 5 (the phases when this information was obtained) were excluded. Each set of models was conducted separately for emotional vitality and optimism.

\section{Results}

\section{Baseline Characteristics}

Of the 7,942 participants, 5,488 were men and 2,454 were women. Ages ranged from 39 to 63 years at baseline $(M=49.51, S D=6.06)$. Tables 1 and 2 show baseline characteristics according to tertiles of emotional vitality and optimism, respectively. People low in wellbeing tended to be slightly younger and people high in well-being tended to be non-white. Relative to men, women had lower levels of emotional vitality but not optimism. Lower levels of well-being were evident among people who were not married or cohabitating. Individuals with relatively low levels of well-being were more likely to be current smokers, exercise less, and eat fewer fruits and vegetables relative to individuals with high levels. Blood pressure, lipids, BMI, and diabetic status did not differ appreciably across levels of well-being.

\section{Positive Psychological Well-Being and Coronary Heart Disease}

There were 291 cases of incident CHD during follow-up. In age-adjusted models, greater emotional vitality demonstrated a protective effect against incident CHD; for each standard deviation increase in emotional vitality, there was a 10\% decrease in the risk of CHD (Table 3 , model 1). A similar pattern was evident for optimism, with a $13 \%$ decrease in the risk of CHD (Table 3, model 1). Adding demographic information to the age-adjusted models did not alter the pattern of findings for either emotional vitality or optimism (Table 3, model 2).

To investigate possible pathways, subsequent models added health-related behaviors and blood pressure/metabolic factors. The addition of behaviors did not alter the findings for emotional vitality or optimism (Table 3, model 3). That is, the reduction in risk of CHD was maintained at $13 \%$. Furthermore, the addition of blood pressure/metabolic factors did not meaningfully change the findings (Table 3, model 4). These results suggest that available measures of lifestyle characteristics and biological processes did not account for the observed association between well-being and CHD.

To establish the independent effects of well-being on CHD, ill-being was added to the fullyadjusted models of both emotional vitality and optimism (Table 3, model 5). Although the association between well-being and CHD was slightly attenuated with the addition of illbeing, an $11 \%$ and $13 \%$ reduction in CHD risk was still evident for emotional vitality and optimism, respectively. In multivariate analyses that included ill-being but not well-being, ill-being demonstrated a comparable effect to well-being $(H R=1.13,95 \% \mathrm{CI}=1.02$ to 1.25). That is, for each standard deviation increase in ill-being, there was a $13 \%$ increase in the risk of CHD. Moreover, similar to well-being, when ill-being and well-being were included in the models simultaneously, effects of ill-being on risk of CHD were somewhat attenuated (emotional vitality model: $H R=1.07,95 \% \mathrm{CI}=0.95$ to 1.21 ; optimism model: $H R=1.10,95 \% \mathrm{CI}=0.98$ to 1.22 ). 
Well-being was categorized into tertiles to examine whether threshold effects were present. Moderate to high levels of emotional vitality and optimism were associated with approximately 20-30\% reduced risk of incident CHD relative to low levels (Table 4), and findings were generally maintained after controlling for the broad range of risk factors.

Stratification by gender indicated that the association between well-being and CHD was similar across men and women, with only slight differences in magnitude (Table 5). Moreover, the interactions between gender and well-being were non-significant in minimally-adjusted and multivariate-adjusted models $(p>0.40)$. Multivariate models stratified by age yielded similar findings for individuals younger than 55 and individuals 55 and older (i.e., the interactions between age and well-being were $p>0.40$ ). For emotional vitality, the $H R$ for younger individuals was $0.91(95 \% \mathrm{CI}=0.78$ to 1.07$)$ and 0.82 for older individuals ( $95 \% \mathrm{CI}=0.78$ to 1.07 ). For optimism, the $H R$ for younger individuals was 0.87 ( $95 \% \mathrm{CI}=0.75$ to 1.01 ) and 0.83 for older individuals (95\% CI $=0.71$ to 0.98 ). Because power is reduced in stratified analyses, these findings warrant cautious interpretations. Nonetheless, it appears that well-being is protective for both genders and for both younger and older individuals.

\section{Additional Analyses}

To examine whether the pattern of findings with the combined outcome of CHD was similar when considering CHD outcomes separately, fatal CHD and non-fatal MI events were analyzed apart from definite angina. For fatal CHD and non-fatal MI, the point estimates remained essentially unchanged in minimally-adjusted models with tertiled well-being, although the overall results were less precise likely due to reduced power (high emotional vitality: $H R=0.75,95 \% \mathrm{CI}=0.50$ to 1.13 ; moderate emotional vitality: $H R=0.82,95 \% \mathrm{CI}$ $=0.55$ to 1.23 ; high optimism: $H R=0.75,95 \% \mathrm{CI}=0.49$ to 1.17 ; moderate optimism: $H R=$ $0.79,95 \% \mathrm{CI}=0.55$ to 1.15 ). Findings from minimally-adjusted models of definite angina were also comparable to the combined outcome of CHD (high emotional vitality: $H R=0.62$, $95 \% \mathrm{CI}=0.44$ to 0.88 ; moderate emotional vitality: $H R=0.75,95 \% \mathrm{CI}=0.54$ to 1.06 ; high optimism: $H R=0.58,95 \% \mathrm{CI}=0.40$ to 0.84 ; moderate optimism: $H R=0.58,95 \% \mathrm{CI}=$ 0.42 to 0.80$)$.

To assess the possibility that people with lower well-being had undetected disease at baseline, the association between well-being and CHD was examined after excluding cases of CHD that developed within 1 person-year of baseline. This conservative approach yielded findings identical to those described above. Additional analyses considered whether findings were substantially altered after excluding individuals with diabetes or individuals who had been told they had high blood pressure. Models that excluded people with diabetes $(n=80)$ did not differ from models that included them and models that excluded people with high blood pressure were unchanged from the models already described.

\section{Discussion}

The current research investigated the association of two different measures of positive psychological well-being - emotional vitality and optimism - with incident CHD in a middle-aged cohort. Higher levels of well-being were consistently associated with reduced risk of CHD over a mean follow-up period of 5 person-years. Notably, the association between well-being and CHD was not explained by health behaviors or biological risk factors, even though individuals with high well-being were healthier with respect to both. Moreover, the association between well-being and CHD was largely maintained after accounting for ill-being. 
Similar to the findings with well-being, a relatively modest effect of ill-being on CHD risk was found in this sample, regardless of which ill-being measure was used. Given the limited measures of psychological functioning available for this study, it is possible that the attenuated effects for both well-being and ill-being when investigated simultaneously are due to the less-than-perfect measurement of both constructs. Moreover, given that neither well-being nor ill-being maintained large effects in the presence of the other, concluding that ill-being is the primary operative factor in the association between psychological health and CHD could be premature. These findings may cast new light on past work regarding the association between ill-being and CHD, as most studies have not considered ill-being in conjunction with well-being. Conclusions may differ somewhat if all studies were able to account for both ill-being and well-being, especially because other work suggests that the absence of ill-being does not necessarily imply the presence of well-being (Ryff et al., 2006). Although it remains likely that well-being and ill-being are relatively independent, this conclusion will be strengthened with additional research that can consider both constructs within the same study, using stronger measures of psychological health.

Other results suggest that threshold effects were present such that risk of CHD was reduced at both moderate and high levels of well-being. Stratified analyses demonstrated nearly equivalent effects for men and women, as well as for younger and older individuals. Although additional analyses largely replicated the pattern of findings after separating fatal CHD and non-fatal MI from definite angina, findings were somewhat stronger for angina. Prior work has found equally strong effects of well-being with both "hard" and "soft" CHD outcomes (Kubzansky et al., 2001), suggesting that smaller effects in the current study for fatal CHD and non-fatal MI could be due to the limited case counts available for this analysis. However, these findings should be interpreted cautiously until further replication.

Overall, the findings reported here (showing approximately $10 \%$ to $25 \%$ reduced risk of a coronary event with every unit increase in positive psychological well-being) are consistent with the magnitude of effects of these types of exposures considered in previous work (Giltay et al., 2006; Kubzansky \& Thurston, 2007) and extend the literature by examining a cohort of mostly middle-age (rather than elderly) men and women. Although effect sizes were modest, the consistency across all analyses is notable, and the varying width of the confidence intervals is likely due to changes in power. Moreover, even after controlling for plausible risk factors, results replicated across two distinct measures of well-being and three definitions of $\mathrm{CHD}$, further enhancing confidence in the findings.

One limitation of the present study concerns generalizability. Individuals in the Whitehall II cohort were from a restricted age range, were relatively healthy, and did not include blue collar workers or the unemployed. Hence, the findings may not characterize the general population. In addition, the well-being measures used in the present research have not been used previously. However, both emotional vitality and optimism demonstrated good face validity and correlations between well-being and other psychosocial factors were as expected, providing evidence for their construct validity.

Previous research with the Whitehall II cohort reported no association between positive affect - another construct within the broad category of positive psychological well-being and incident CHD (Nabi et al., 2008). One way to account for the discrepancy between the previous investigation and the current one is to recognize that well-being is comprised of distinct but overlapping domains: eudaimonic well-being, hedonic well-being, and social well-being (Gallagher et al., 2009; Ryan \& Deci, 2001). Whereas emotional vitality and optimism can each be categorized as eudaimonic well-being, positive affect is categorized as hedonic well-being. Recent evidence suggests that eudaimonic and hedonic well-being have different relationships with physical health (Ryff, Singer, \& Love, 2004). Thus, 
distinguishing between the two (and investigating the role of interpersonal well-being) may be critical to future investigations in this area.

Despite attempts at identifying pathways by which well-being may lead to CHD, the mechanisms tested in the current investigation did not account for the relationship. It is possible that effects were not found because the measures were insufficiently precise or because change in the measures was not assessed over time. However, previous reports from the Whitehall II cohort have shown robust associations between conventional risk factors and CHD (Kivimaki et al., 2005). Furthermore, other work has also failed to find that these factors adequately explain observed effects of well-being on CHD (Kubzansky \& Thurston, 2007; Tindle et al., 2009). Thus, future research should consider other factors, both psychosocial and physiologic, that may mediate the relationship. For example, one of the strongest correlates of well-being is the presence of close social relationships (Diener \& Seligman, 2002). Social relationships may serve to buffer against physiological reactivity or encourage healthy behaviors, thereby reducing risk for CHD. Furthermore, other physiologically-based mechanisms not tested here may mediate the relationship. Specifically, aldosterone, heart rate, and inflammatory markers (e.g., interleukin-6, Creactive protein, and fibrinogen) are considered risk factors for $\mathrm{CHD}$ and are associated with well-being (Kubzansky \& Adler, 2010; Steptoe et al., 2009).

Another direction for future research is whether clinical interventions designed to boost well-being can also reduce the risk of CHD. Although interventions to alleviate distress have yielded inconsistent results for cardiovascular health (e.g., Berkman et al., 2003), evidence suggests that focusing on positive functioning may enhance an individual's ability to deal with challenges (Rozanski \& Kubzansky, 2005). Preliminary evidence also suggests that well-being can be sustainably increased (Seligman, Steen, Park, \& Peterson, 2005; Sheldon \& Lyubomirsky, 2006). Thus, in addition to focusing on decreasing psychological ill-being in the context of cardiovascular health, it may also be effective for clinicians to encourage the development of positive affect and cognitions, meaningful life pursuits, and personal strengths (Seligman et al., 2005). Indeed, at least one clinical trial involving cardiac patients is currently underway to investigate whether enhancement of positive psychological wellbeing impacts health-related outcomes (Charlson et al., 2007).

In summary, this prospective investigation of middle-aged men and women suggests that positive psychological well-being reduces risk of incident CHD, even when accounting for cardiovascular risk factors and ill-being. Although more work remains to be done regarding the pathways linking well-being to CHD, this investigation indicates that positive psychological well-being is not only an important outcome in its own right, but may have far-reaching consequences for cardiovascular health.

\section{Acknowledgments}

This study was supported by the Robert Wood Johnson Foundation Grant ID 63597, Positive Health: The Copenhagen-Medici Model. We thank all participants in the Whitehall II Study, along with participating Civil Service departments, the Occupational Health and Safety Agency, and the Council of Civil Service Unions. In addition, we appreciate the efforts of the Whitehall II Study research team. Ongoing data collection is funded by the Medical Research Council, National Institute on Aging (AG13196), National Heart Lung and Blood Institute (HL36310), and British Heart Foundation.

\section{References}

Berkman LF, Blumenthal J, Burg M, Carney RM, Catellier D, Cowan MJ, et al. Effects of treating depression and low perceived social support on clinical events after myocardial infarction: The Enhancing Recovery in Coronary Heart Disease Patients (ENRICHD) Randomized Trial. JAMA. 2003; 289:3106-3116. [PubMed: 12813116] 
Charlson ME, Boutin-Foster C, Mancuso CA, Peterson JC, Ogedegbe G, Briggs WM, et al. Randomized controlled trials of positive affect and self-affirmation to facilitate healthy behaviors in patients with cardiopulmonary diseases: Rationale, trial design, and methods. Contemporary Clinical Trials. 2007; 28:748-762. [PubMed: 17459784]

Davidson KW, Mostofsky E, Whang W. Don't worry, be happy: Positive affect and reduced 10-year incident coronary heart disease: The Canadian Nova Scotia Health Survey. European Heart Journal. 2010; 31:1065-1070. [PubMed: 20164244]

Diener E, Seligman ME. Very happy people. Psychological Science. 2002; 13:81-84. [PubMed: 11894851]

Gallagher MW, Lopez SJ, Preacher KJ. The hierarchical structure of well-being. Journal of Personality. 2009; 77:1025-1050. [PubMed: 19558444]

Giltay EJ, Geleijnse JM, Zitman FG, Buijsse B, Kromhout D. Lifestyle and dietary correlates of dispositional optimism in men: The Zutphen Elderly Study. Journal of Psychosomatic Research. 2007; 63:483-490. [PubMed: 17980220]

Giltay EJ, Kamphuis MH, Kalmijn S, Zitman FG, Kromhout D. Dispositional optimism and the risk of cardiovascular death: The Zutphen Elderly Study. Archives of Internal Medicine. 2006; 166:431436. [PubMed: 16505263]

Graham JW. Missing data analysis: Making it work in the real world. Annual Review of Psychology. 2009; 60:549-576.

Kashdan TB, Biswas-Diener R, King LA. Reconsidering happiness: The costs of distinguishing between hedonics and eudaimonia. The Journal of Positive Psychology. 2008; 3:219-233.

Keyes CLM, Annas J. Feeling good and functioning well: Distinctive concepts in ancient philosophy and contemporary science. The Journal of Positive Psychology. 2009; 4:197-201.

Kivimaki M, Ferrie JE, Brunner E, Head J, Shipley MJ, Vahtera J, et al. Justice at work and reduced risk of coronary heart disease among employees: The Whitehall II Study. Archives of Internal Medicine. 2005; 165:2245-2251. [PubMed: 16246990]

Koizumi M, Ito H, Kaneko Y, Motohashi Y. Effect of having a sense of purpose in life on the risk of death from cardiovascular diseases. Journal of Epidemiology. 2008; 18:191-196. [PubMed: 18753736]

Kubzansky LD, Adler GK. Aldosterone: A forgotten mediator of the relationship between psychological stress and heart disease. Neuroscience and Biobehavioral Reviews. 2010; 34:80-86. [PubMed: 19631234]

Kubzansky LD, Sparrow D, Vokonas P, Kawachi I. Is the glass half empty or half full? A prospective study of optimism and coronary heart disease in the Normative Aging Study. Psychosomatic Medicine. 2001; 63:910-916. [PubMed: 11719629]

Kubzansky LD, Thurston RC. Emotional vitality and incident coronary heart disease: Benefits of healthy psychological functioning. Archives of General Psychiatry. 2007; 64:1393-1401. [PubMed: 18056547]

Marmot MG, Smith GD, Stansfeld S, Patel C, North F, Head J, et al. Health inequalities among British civil servants: The Whitehall II study. Lancet. 1991; 337:1387-1393. [PubMed: 1674771]

Mathers CD, Loncar D. Projections of global mortality and burden of disease from 2002 to 2030. PLoS Medicine. 2006; 3:e442. [PubMed: 17132052]

Nabi H, Kivimaki M, De Vogli R, Marmot MG, Singh-Manoux A. Positive and negative affect and risk of coronary heart disease: Whitehall II prospective cohort study. BMJ (Clinical Research Ed.). 2008; 337:a118.

Rose, GA.; Blackburn, H.; Gillum, RF.; Prineas, RJ. Cardiovascular survey methods. 2nd ed. World Health Organization; Geneva: 1982.

Rozanski A, Kubzansky LD. Psychologic functioning and physical health: A paradigm of flexibility. Psychosomatic Medicine. 2005; 67(Suppl 1):S47-53. [PubMed: 15953801]

Ryan RM, Deci EL. On happiness and human potentials: A review of research on hedonic and eudaimonic well-being. Annual Review of Psychology. 2001; 52:141-166.

Ryff CD, Love GD, Urry HL, Muller D, Rosenkranz MA, Friedman EM, et al. Psychological wellbeing and ill-being: Do they have distinct or mirrored biological correlates? Psychotherapy and Psychosomatics. 2006; 75:85-95. [PubMed: 16508343] 
Ryff CD, Singer B. The contours of positive human health. Psychological Inquiry. 1998; 9:1-28.

Ryff CD, Singer BH, Love GD. Positive health: Connecting well-being with biology. Philosophical Transactions of the Royal Society B. 2004; 359:1383-1394.

Scheier MF, Carver CS. Optimism, coping, and health: Assessment and implications of generalized outcome expectancies. Health Psychology. 1985; 4:219-247. [PubMed: 4029106]

Seligman MEP, Steen TA, Park N, Peterson C. Positive psychology progress: Empirical validation of interventions. American Psychologist. 2005; 60:410-421. [PubMed: 16045394]

Sheldon KM, Lyubomirsky S. How to increase and sustain positive emotion: The effects of expressing gratitude and visualizing best possible selves. The Journal of Positive Psychology. 2006; 1:73-82.

Steptoe A, Dockray S, Wardle J. Positive affect and psychobiological processes relevant to health. Journal of Personality. 2009; 77:1747-1776. [PubMed: 19796062]

Steptoe A, Wright C, Kunz-Ebrecht SR, Iliffe S. Dispositional optimism and health behaviour in community-dwelling older people: Associations with healthy ageing. British Journal of Health Psychology. 2006; 11:71-84. [PubMed: 16480556]

Tanno K, Sakata K, Ohsawa M, Onoda T, Itai K, Yaegashi Y, et al. Associations of ikigai as a positive psychological factor with all-cause mortality and cause-specific mortality among middle-aged and elderly Japanese people: Findings from the Japan Collaborative Cohort Study. Journal of Psychosomatic Research. 2009; 67:67-75. [PubMed: 19539820]

Tindle HA, Chang YF, Kuller LH, Manson JE, Robinson JG, Rosal MC, et al. Optimism, cynical hostility, and incident coronary heart disease and mortality in the Women's Health Initiative. Circulation. 2009; 120:656-662. [PubMed: 19667234]

Tunstall-Pedoe H, Kuulasmaa K, Amouyel P, Arveiler D, Rajakangas AM, Pajak A. Myocardial infarction and coronary deaths in the World Health Organization MONICA Project. Registration procedures, event rates, and case-fatality rates in 38 populations from 21 countries in four continents. Circulation. 1994; 90:583-612. [PubMed: 8026046]

Ware J, Sherbourne C. The MOS 36-item short-form health survey (SF-36). Conceptual framework and item selection. Medical Care. 1992; 30:473-483. [PubMed: 1593914]

Xu, J.; Kochanek, KD.; Murphy, SL.; Tejada-Vera, B. Deaths: Final Data for 2007. National Center for Health Statistics; Hyattsville, MD: 2010.

Yusuf S, Hawken S, Ounpuu S, Dans T, Avezum A, Lanas F, et al. Effect of potentially modifiable risk factors associated with myocardial infarction in 52 countries (the INTERHEART study): Case-control study. Lancet. 2004; 364:937-952. [PubMed: 15364185] 
Table 1

Distribution of Coronary Risk Factors According to Level of Emotional Vitality

\begin{tabular}{|c|c|c|c|}
\hline \multirow[b]{2}{*}{ Risk Factor } & \multicolumn{3}{|c|}{ Emotional Vitality } \\
\hline & $\begin{array}{c}\text { Low } \\
n=2,641\end{array}$ & $\begin{array}{l}\text { Moderate } \\
n=2,681\end{array}$ & $\begin{array}{c}\text { High } \\
n=2,620\end{array}$ \\
\hline Mean age (SD) & $48.40(5.74)$ & $49.43(6.05)$ & $50.72(6.17)$ \\
\hline \multicolumn{4}{|l|}{ Gender } \\
\hline Male & $1,731(65.54 \%)$ & $1,867(69.64 \%)$ & $1,890(72.14 \%)$ \\
\hline Female & $910(34.46 \%)$ & $814(30.36 \%)$ & $730(27.86 \%)$ \\
\hline \multicolumn{4}{|l|}{ Ethnicity } \\
\hline White & $2,482(93.98 \%)$ & $2,443(91.12 \%)$ & $2,293(87.52 \%)$ \\
\hline Non-white & $159(6.02 \%)$ & $238(8.88 \%)$ & $327(12.48 \%)$ \\
\hline \multicolumn{4}{|l|}{ Marital status } \\
\hline Married or cohabitating & $1,828(69.27 \%)$ & $2,098(78.25 \%)$ & $2,144(82.02 \%)$ \\
\hline Other & $811(30.73 \%)$ & $583(21.75 \%)$ & $470(17.98 \%)$ \\
\hline \multicolumn{4}{|l|}{ Grade of employment } \\
\hline Administrative & $994(37.69 \%)$ & $1,059(39.51 \%)$ & $1,017(38.85 \%)$ \\
\hline Professional & $1,269(48.12 \%)$ & $1,172(43.73 \%)$ & $1,141(43.58 \%)$ \\
\hline Clerical & $374(14.18 \%)$ & $449(16.75 \%)$ & $460(17.57 \%)$ \\
\hline \multicolumn{4}{|l|}{ Smoking status } \\
\hline Never smoker & $1,273(49.30 \%)$ & $1,361(51.93 \%)$ & $1,360(52.73 \%)$ \\
\hline Former smoker & $900(34.86 \%)$ & $888(33.88 \%)$ & $917(35.56 \%)$ \\
\hline Current smoker & $409(15.84 \%)$ & $372(14.19 \%)$ & $302(11.71 \%)$ \\
\hline Mean alcohol consumption (SD) & $10.28(12.82)$ & $10.84(13.55)$ & $9.48(11.70)$ \\
\hline Mean exercise (SD) & $9.49(8.06)$ & $10.17(8.72)$ & $11.49(10.46)$ \\
\hline \multicolumn{4}{|l|}{ Fruit and vegetable consumption } \\
\hline Yes & $1,556(58.92 \%)$ & $1,605(59.87 \%)$ & $1,732(66.11 \%)$ \\
\hline No & $1,085(41.08 \%)$ & $1,076(40.13 \%)$ & $888(33.89 \%)$ \\
\hline Mean SBP (SD), mm Hg & $119.23(13.07)$ & $120.50(13.63)$ & $121.77(13.72)$ \\
\hline Mean DBP (SD), mm Hg & $79.06(9.35)$ & $79.84(9.39)$ & $80.08(9.42)$ \\
\hline Mean HDL-C (SD), mmol/L & $1.44(0.42)$ & $1.43(0.40)$ & $1.43(0.41)$ \\
\hline Mean LDL-C (SD), mmol/L & $4.33(1.01)$ & $4.39(1.05)$ & $4.44(1.05)$ \\
\hline Mean triglycerides (SD), $\mathrm{mmol} / \mathrm{L}$ & $1.45(1.00)$ & $1.51(1.26)$ & $1.45(1.08)$ \\
\hline Mean BMI (SD), kg/m² & $25.12(3.84)$ & $25.32(3.64)$ & $25.31(3.60)$ \\
\hline \multicolumn{4}{|l|}{ Diabetes } \\
\hline No & $2,613(99.01 \%)$ & $2,648(98.84 \%)$ & $2,595(99.12 \%)$ \\
\hline Yes & $26(0.99 \%)$ & $31(1.16 \%)$ & $23(0.88 \%)$ \\
\hline
\end{tabular}

Abbreviations: BMI, body mass index; DBP, diastolic blood pressure; HDL-C, high-density lipoprotein cholesterol; LDL-C, low-density lipoprotein cholesterol; SBP, systolic blood pressure; SD, standard deviation.

Note: Percentages refer to the column percent of individuals within each emotional vitality category with that characteristic. 
Table 2

Distribution of Coronary Risk Factors According to Level of Optimism Optimism

\begin{tabular}{|c|c|c|c|}
\hline \multirow[b]{2}{*}{ Risk Factor } & \multicolumn{3}{|c|}{ Optimism } \\
\hline & $\begin{array}{c}\text { Low } \\
n=2,943\end{array}$ & $\begin{array}{l}\text { Moderate } \\
n=3,136\end{array}$ & $\begin{array}{c}\text { High } \\
n=1,863\end{array}$ \\
\hline Mean age (SD) & $48.95(5.91)$ & $49.73(6.17)$ & $50.03(6.05)$ \\
\hline \multicolumn{4}{|l|}{ Gender } \\
\hline Male & $2,045(69.49 \%)$ & $2,180(69.52 \%)$ & $1,263(67.79 \%)$ \\
\hline Female & $898(30.51 \%)$ & $956(30.48 \%)$ & $600(32.21 \%)$ \\
\hline \multicolumn{4}{|l|}{ Ethnicity } \\
\hline White & $2,710(92.08 \%)$ & $2,853(90.98 \%)$ & $1,655(88.84 \%)$ \\
\hline Non-white & $233(7.92 \%)$ & $283(9.02 \%)$ & $208(11.16 \%)$ \\
\hline \multicolumn{4}{|l|}{ Marital status } \\
\hline Married or cohabitating & $2,130(72.40 \%)$ & $2,474(78.94 \%)$ & $1,466(78.90 \%)$ \\
\hline Other & $812(27.60 \%)$ & $660(21.06 \%)$ & $392(21.10 \%)$ \\
\hline \multicolumn{4}{|l|}{ Grade of employment } \\
\hline Administrative & $1,048(35.63 \%)$ & $1,270(40.55 \%)$ & $752(40.39 \%)$ \\
\hline Professional & $1,370(46.58 \%)$ & $1,371(43.77 \%)$ & $841(45.17 \%)$ \\
\hline Clerical & $523(17.78 \%)$ & $491(15.68 \%)$ & $269(14.45 \%)$ \\
\hline \multicolumn{4}{|l|}{ Smoking status } \\
\hline Never smoker & $1,434(49.83 \%)$ & $1,609(52.36 \%)$ & $951(51.94 \%)$ \\
\hline Former smoker & $960(33.36 \%)$ & $1,087(35.37 \%)$ & $658(35.94 \%)$ \\
\hline Current smoker & $484(16.82 \%)$ & $377(12.27 \%)$ & $222(12.12 \%)$ \\
\hline Mean alcohol consumption (SD) & $10.11(12.69)$ & $10.42(13.00)$ & $9.98(12.32)$ \\
\hline Mean exercise (SD) & $9.54(8.33)$ & $10.51(9.14)$ & $11.47(10.29)$ \\
\hline \multicolumn{4}{|l|}{ Fruit and vegetable consumption } \\
\hline Yes & $1,709(58.07 \%)$ & $1,965(62.66 \%)$ & $1,219(65.43 \%)$ \\
\hline No & $1,234(41.93 \%)$ & $1,171(37.34 \%)$ & $644(34.57 \%)$ \\
\hline Mean SBP (SD), mm Hg & $119.99(13.36)$ & $120.86(13.72)$ & $120.68(13.38)$ \\
\hline Mean DBP (SD), mm Hg & $79.39(9.37)$ & $79.82(9.50)$ & $79.81(9.24)$ \\
\hline Mean HDL-C (SD), mmol/L & $1.43(0.41)$ & $1.43(0.40)$ & $1.45(0.42)$ \\
\hline Mean LDL-C (SD), mmol/L & $4.36(1.02)$ & $4.41(1.04)$ & $4.39(1.05)$ \\
\hline Mean triglycerides $(\mathrm{SD}), \mathrm{mmol} / \mathrm{L}$ & $1.47(1.15)$ & $1.48(1.12)$ & $1.46(1.07)$ \\
\hline Mean BMI (SD), $\mathrm{kg} / \mathrm{m}^{2}$ & $25.12(3.66)$ & $25.26(3.64)$ & $25.45(3.85)$ \\
\hline \multicolumn{4}{|l|}{ Diabetes } \\
\hline No & $2,919(99.25 \%)$ & $3,100(98.92 \%)$ & $1,837(98.71 \%)$ \\
\hline Yes & $22(0.75 \%)$ & $34(1.08 \%)$ & $24(1.29 \%)$ \\
\hline
\end{tabular}

Abbreviations: BMI, body mass index; DBP, diastolic blood pressure; HDL-C, high-density lipoprotein cholesterol; LDL-C, low-density lipoprotein cholesterol; SBP, systolic blood pressure; SD, standard deviation.

Note: Percentages refer to the column percent of individuals within each optimism category with that characteristic. 


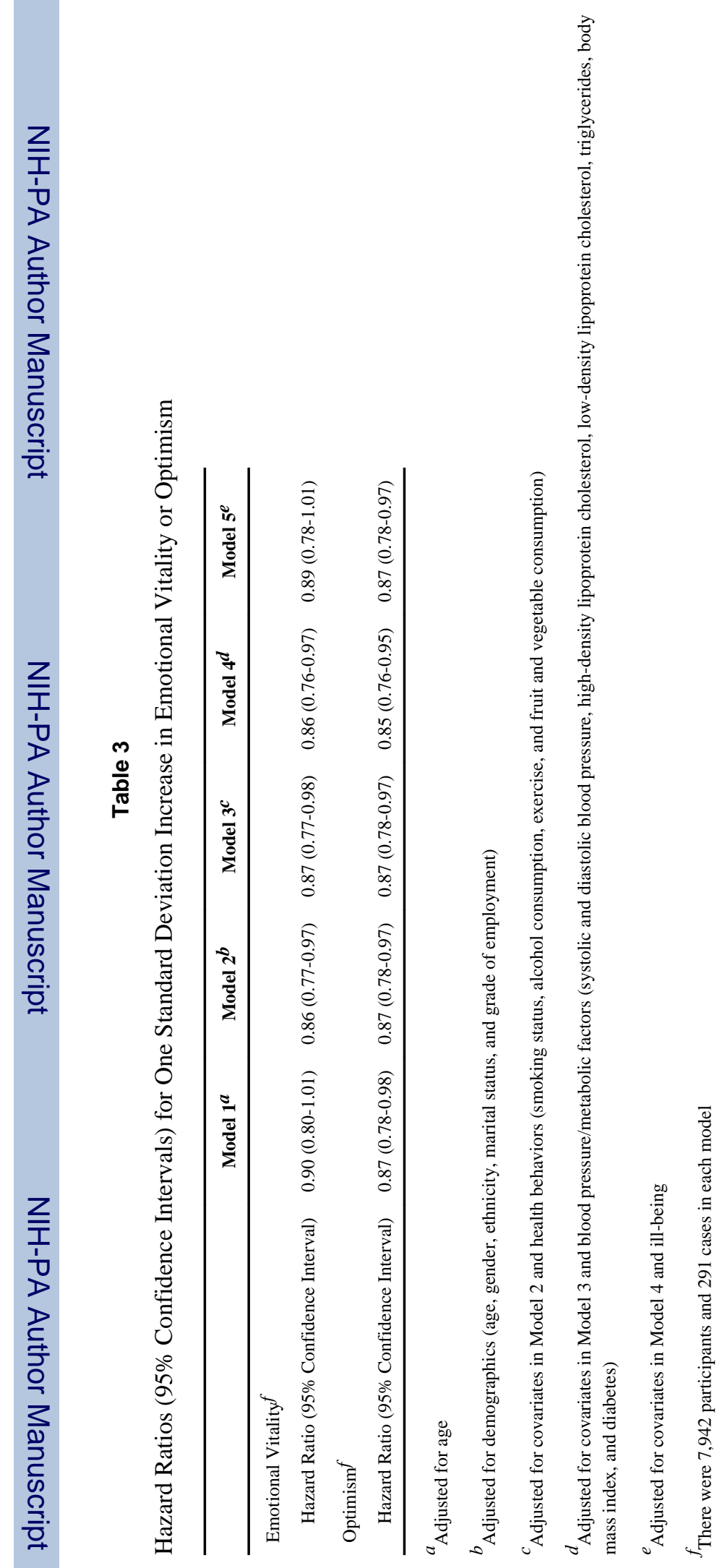

Health Psychol. Author manuscript; available in PMC 2012 May 1. 
Table 4

Minimally- and Multivariate-Adjusted Hazard Ratios (95\% Confidence Intervals) According to Level of Emotional Vitality or Optimism

\begin{tabular}{|c|c|c|c|c|}
\hline & \multicolumn{3}{|c|}{ Hazard Ratio (95\% Confidence Interval) } & \\
\hline & \multicolumn{3}{|c|}{ Positive Psychological Well-Being } & \\
\hline & Low & Moderate & High & \\
\hline \multicolumn{5}{|l|}{ Emotional Vitality } \\
\hline Number of Cases ${ }^{a}$ & 101 & 94 & 96 & \\
\hline Minimally-Adjusted $^{b}$ & 1.00 & $0.81(0.61-1.07)$ & $0.74(0.55-0.98)$ & \\
\hline Multivariate-Adjusted $^{c}$ & 1.00 & $0.79(0.59-1.04)$ & $0.72(0.54-0.97)$ & \\
\hline \multicolumn{5}{|l|}{ Optimism } \\
\hline Number of Cases ${ }^{a}$ & 126 & 99 & 66 & \\
\hline Minimally-Adjusted $b$ & 1.00 & $0.68(0.52-0.88)$ & $0.73(0.54-0.99)$ & \\
\hline Multivariate-Adjusted $^{c}$ & 1.00 & $0.66(0.51-0.87)$ & $0.69(0.51-0.94)$ & \\
\hline There were 7,942 participar & and 2 & 91 cases in each m & & \\
\hline
\end{tabular}


Table 5

Hazard Ratios (95\% Confidence Intervals) for One Standard Deviation Increase in Emotional Vitality or Optimism According to Gender

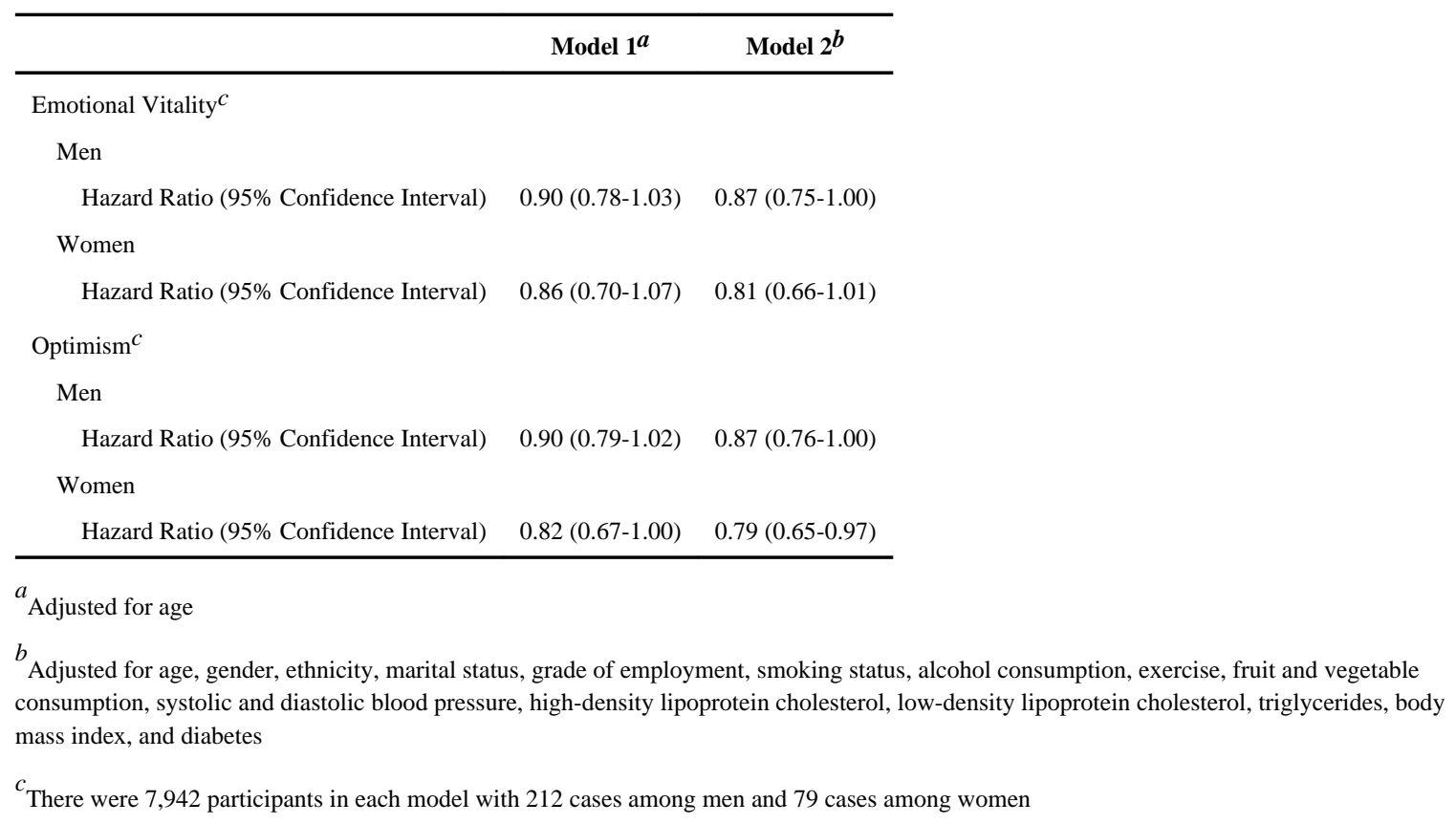

